\title{
Thermal Simulation of Compact Self-ballasted Fluorescent Lamps
}

\author{
Hisashi HONDA, Yooji YUGE, Hidenori ITOH \\ Toshiba Lighting \& Technology Corp. \\ 1-201-1 Hunakoshi-cho, Yokosuka, Kanagawa 237 Japan \\ Masaru ISHIZUKA, Tomiya SASAKI \\ Toshiba Corp. \\ 4-1 Ukishima-cho, Kawasaki-ku, Kanagawa 201 Japan \\ Paper originally published in Japanese in J.IEIJ, Vol.73, No2 (1989)
}

\begin{abstract}
Thermal design is one of the most important issues in developing compact self-ballasted fluorescent lamps which are required to be in smaller size and with higher output. In this paper, a simulation model is proposed using thermal network equations.

The thermal network equations are derived from the theoretical system consisting of thermal circuit which is analogous with an electric circuit. The coefficients of the thermal network equations can be obtained by a model experiment using a heater. The calculated temperatures are in good agreement with the measured temperatures. The thermal simulation is useful for designing compact self-ballasted fluorescent lamps.
\end{abstract}

\section{Introduction}

Recently, there has been developed a compact self-ballasted fluorescent lamp, which combined a light tube with an operating circuit. An operating circuit is mounted in a case "a power source case" This type of lamp has been widely used as an alternative light source due to its features of higher efficacy and longer life compared with incandescent lamp. However it is obvious that the trend of the smaller size and higher output of lamp would increase more an amount of heating per unit heat radiation area due to a reduction of heat radiation area and an increase of power supply compared with a conventional compact self-ballasted fluorescent lamp from the view point of thermal problems.

A thermal design will become one of the most important keys for the future development of compact self-ballasted fluorescent lamps with electronic operating circuit consisting of semiconductor parts affected thermally.

A numerical equation model estimating change of temperatures and heat flow on a boundary condition is useful to design thermal problems of lamps. Although a number of general-purpose programs for thermal analysis by means of finite element method is available at present, in such a program a process of input and output is complicated so that it is not appropriate for the thermal analysis of a compact self-ballasted fluorescent lamp having especially complicated heat transfer modes.

In this paper, a simulation model proposed by using thermal network epuations which simplified the thermal analysis of the compact self-ballasted fluorescent lamp is discussed, wherein a minimum number of experimental constants is introduced and they are compared with actual measurement results. That the calculation results and the measurement results have a relatively good agreement in a steady state and that this simulation model is available for a practical design.

\section{Heat Transfer Model}

\subsection{Heat Transfer Model of Compact Self-Ballasted Fluorescent lamp}

A general construction of the compact self-ballasted fluorescent lamp used as our model is shown in Fig. $1^{1)}$. An electronic operating circuit is mounted in a power source case with a lamp base and a light tube is mounted to the power source case by means of insulating plates for shielding a heat flow from the light tube. Now, heat transfer modes to be considerable in the case of this lamp is shown in Fig.2.

It was assumed that the lamp was positioned vertically with a lamp base directed upwards. In this heat transfer mode, the total heating value $Q(W)$ is expressed by Eq. (1).

$$
Q=Q_{L}+Q_{B}
$$

where $Q_{L}$ : lamp power (equivalent heating value from light 


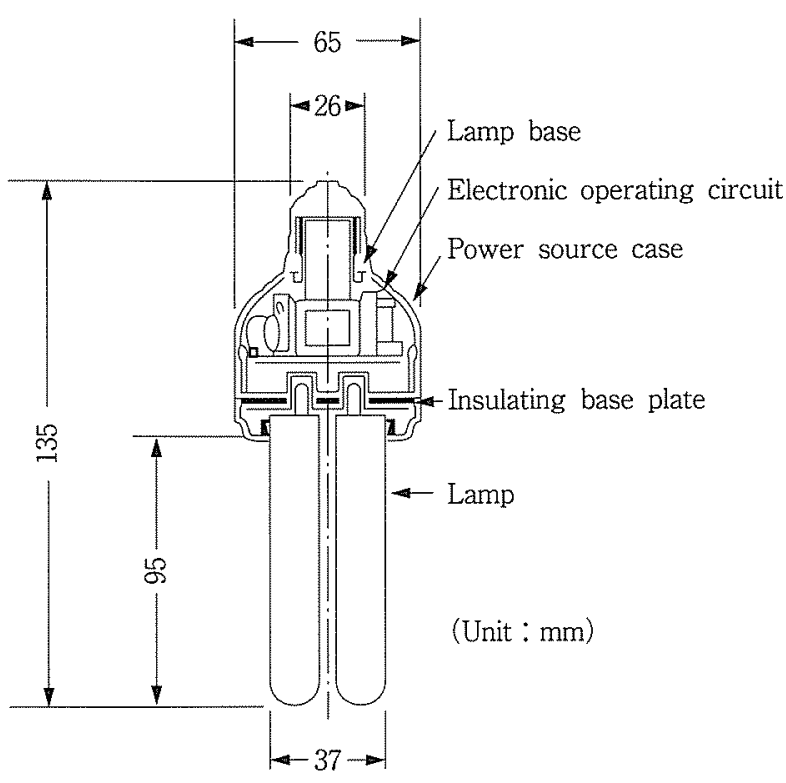

Fig. 1 Construction of compact self-ballasted fluorescent lamp

Total heating value

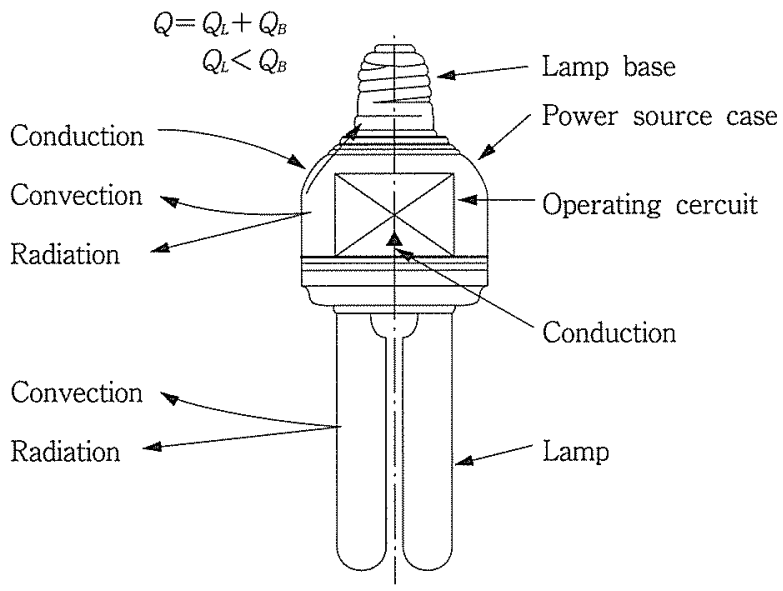

Fig. 2 Heat transfer mode of compact self-ballasted fluorescent lamp

tube) (W)

$Q_{B}:$ heating value from operating circuit (W).

In the case of compact self-ballasted fluorescent lamp, the relation of Eq. (2) is satisfied, generally.

$$
Q_{L}>Q_{B}
$$

And the circuit efficiency $\eta$ is given by Eq. (3)

$$
\eta=Q_{L} / Q
$$

The above-mentioned heat value $Q_{L}, Q_{B}$ is transfered according to one of the following heat transfer modes as shown in Fig. 2.

(1) Heat conduction

(2) Heat radiation

(3) Natural convection

Therefore, in forming a model of heat transfer mode of the compact self-ballasted fluorescent lamp, it is necessary to take into consideration all of these heat transfer modes.
Practically, the following items will be mentioned.

For heat conduction:

(1) Heat flow from light tube to power source case

(2) Heat conduction on light tube and power source case and those temperature distribution

(3) Connection between light tube and power source case by heat

For heat radiation:

(1) Radiation from the surface of light tube, heating element and power source case.

For the influence by natural convection:

(1) Influence by convection from ceiling

(2) Difference between ambient temperature and around power source case and atmospheric temperature.

\subsection{Thermal Network Method}

Now, a thermal network method will be described below. The thermal network method is a method for constructing an electric circuit from a thermal system by replacing the heat flow and temperature with current and potential, respectively, so that the thermal system is completely analogous with the electrical system such that a potential (temperature) difference is shown by the product of heat flow and heat resistance. Table 1 shows a correspondence table between thermal system and electrical system ${ }^{2}$. In the case

Table 1 Correspondence table between thermal system and electrical system

\begin{tabular}{l|l}
\multicolumn{1}{c|}{ Thermal system } & \multicolumn{1}{c}{ Electrical system } \\
\hline Temperature difference & Potential difference \\
Quantity of heat & Quantity of electricity \\
Heat flow & Current \\
Heat conductivity & Conductivity \\
Heat resistance & Resistance \\
heat capacity & Electrostatic capacity \\
\hline
\end{tabular}

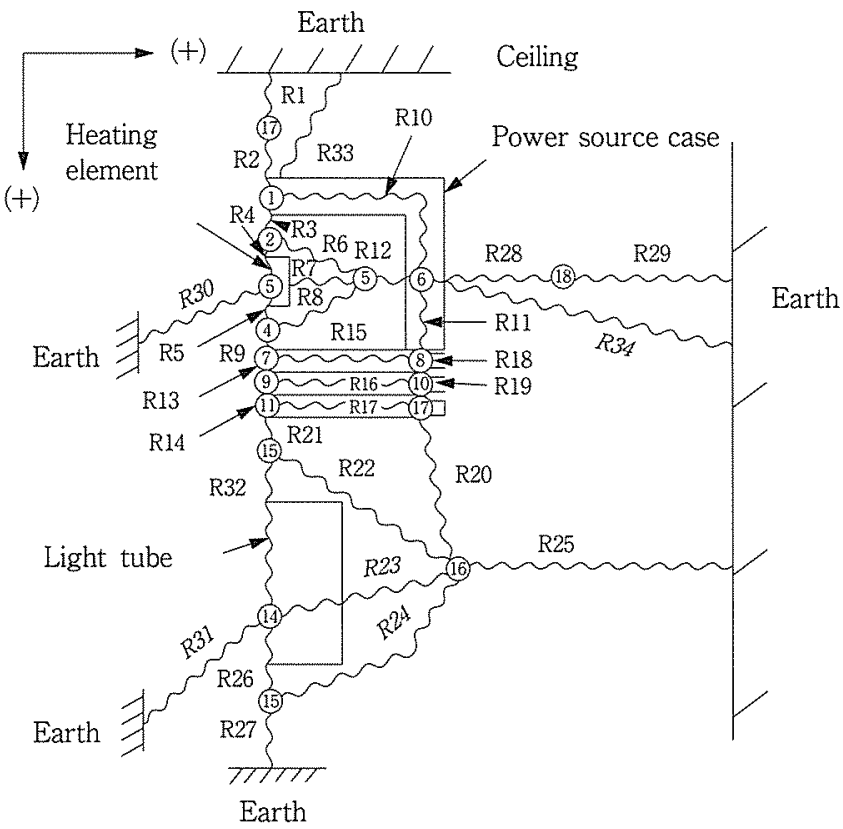

Fig. 3 Thermal network model of compact self-ballasted fluorescent lamp 
of steady state, it is sufficient to take into account a heat resistance only, while in the case of transient state it is necessary to consider the capacitance in addition to the resistance ${ }^{3)}$. In the latter cace, the heat transfer model will become complicate so that it was decided to discuss only a steady state.

The thermal network model corresponding to the compact self-ballasted fluorescent lamp as shown in Fig. 2 is shown in Fig. 3. In Fig. 3, each node shows a representative temperature of some divisional area and each node is connected to each other by a wave-form line, thereby a thermal network being constructed. Table 2 shows a number of areas represented by each temperature node.

\section{Formulation}

\subsection{Thermal Network Equation}

The formulation is thermal network is carried out in accordance with the following two rules:

(1) $\Delta T=R \times Q$

where $R$ : heat resistance $\left({ }^{\circ} \mathrm{C} / \mathrm{W}\right)$

$\Delta T:$ temperature difference $\left({ }^{\circ} \mathrm{C}\right)$

$Q$ : heat flow through $R(\mathrm{~W})$

(2) $\sum Q_{\text {in }}=\Sigma Q_{\text {our }}$

where $Q_{i n}$ : sum of heat flow entering into each temperature node (W)

$Q_{\text {out }}$ : sum of heat flow outgoing from each temperature node $(W)$.

That is to say that for each heat resistance the Ohm's law of electrical system as shown by Eq. (4) is established and for each thermal node the Kirchhoff's law as shown by Eq. (5) is estsablished. For example, in Fig. 3, if the direction from upper to lower and from left to right, respectively, is defined as positive. Eq. (6) is formulated for the heat resistance $R 12$ used for conducting the heat flow from the inside of the power source case to the power source case and a heat balance as shown in Eq. (7) is obtained for the

Table 2 Description of area represented by node number

\begin{tabular}{c|l}
\hline Node No. & \multicolumn{1}{|c}{ Description of node No. } \\
\hline$(1)$ & Lamp base of power source case \\
$(2)$ & Upper air within power source case \\
$(3)$ & Heating element \\
$(4)$ & Lower air within power source case \\
$(5)$ & Side air within power source case \\
$(6)$ & Side portion of power source case \\
$(7)$ & Center of insulating plate (1) \\
$(8)$ & Edge of insulating plate (1) \\
$(9)$ & Center of insulating layer \\
$(10)$ & Edge of insulating layer \\
$(11)$ & Center of insulating plate (2) \\
$(12)$ & Edge of insulating plate (2) \\
$(13)$ & Air above light tube \\
$(14)$ & Surface of light tube \\
$(15)$ & Air below light tube \\
$(16)$ & Air beside light tube \\
$(17)$ & Air above power source case \\
$(18)$ & Air beside power source case \\
\hline
\end{tabular}

thermal node (6) representing the temperature of the surface of power source case.

$$
\begin{aligned}
& T 5-T 6=Q 12 \times R 12 \ldots \ldots \ldots \ldots \\
& Q 10+Q 12=Q 11+Q 28+Q 34
\end{aligned}
$$

In this model, the number of heat resistance is 34 and the number of thermal node is 18 so that totally 52 thermal network equations are formulated by considering the temperature and heat flow as unknown quantity. These euqations are shown in Table 3 .

\subsection{Formulation}

The formulation of heat resistance in Table 3 and Eq. (4) was carried out by taking into account each heat transfer element as shown in the following.

(1) Natural convection heat transfer element (R2, R23, R26, R28)

For example, R28 shows a resistance of heat flow path formed by a natural convection from the surface of power source case. When a heat transfer mode by a natural convection from a cylindrical (if estimated as cylindrical) surface of power source case is considered, the natural convection heat transfer value $Q_{c}(W)$ from its vertical surface is given by Eq. $(8)^{2) 33}$.

$$
Q_{C}=\alpha(\Delta T / L)^{0.25} \cdot A \cdot \Delta T
$$

where $\alpha$ : experimental constant

$\Delta T$ : (upstream temperature-downstream temperature) $\left({ }^{\circ} \mathrm{C}\right)$

Table 3 Thermal network equations
(1) $T \infty-T 17=Q 1 \times R 1$
(2) $\mathrm{T} 17-\mathrm{T} 1=\mathrm{Q} 2 \times \mathrm{R} 2$
(3) $T 1-T 2=Q 3 \times R 3$
(4) $\mathrm{T} 2-\mathrm{T} 3=\mathrm{Q} 4 \times \mathrm{R} 4$
(5) $\mathrm{T} 3-\mathrm{T} 4=\mathrm{Q} 5 \times \mathrm{R} 5$
(6) $\mathrm{T} 2-\mathrm{T} 5=\mathrm{Q} 6 \times \mathrm{R} 6$
(7) $T 3-T 5=Q 7 \times R 7$
(8) $T 4-T 5=Q 8 \times R 8$
(9) $T 4-T 7=Q 9 \times R 9$
(10) $T 1-T 6=Q 10 \times R 10$
(11) $\mathrm{T} 6-\mathrm{T} 8=Q 11 \times R 11$
(12) $T 5-T 6=Q 12 \times R 12$
(13) $T 7-T 9=Q 13 \times R 13$
(14) $T 9-T 11=Q 14 \times R 14$
(15) $T 7-T 8=Q 15 \times R 15$
(16) $T 9-T 10=Q 16 \times R 16$
(17) $T 11-T 12=Q 17 \times R 17$
(18) $T 8-T 10=Q 18 \times R 18$
(19) $T 10-T 12=Q 19 \times R 19$
(20) $T 12-T 16=Q 20 \times R 20$
(21) $T 11-T 13=Q 21 \times R 21$
(22) $T 13-T 16=Q 22 \times R 22$
(23) $T 14-T 16=Q 23 \times R 23$
(24) $T 15-T 16=Q 24 \times R 24$
(25) $T 16-T \infty=Q 25 \times R 25$
(26) $T 14-T 15=Q 26 \times R 26$
(27) $T 15-T \infty=Q 27 \times R 27$
(28) $T 6-T 18=Q 28 \times R 28$
(29) $T 18-T \infty=Q 29 \times R 29$
(30) $T 3-T \infty=Q 30 \times R 30$
(31) $T 14-T \infty=Q 31 \times R 31$
(32) $T 13-T 14=Q 32 \times R 32$
(33) $T 1-T \infty=Q 33 \times R 33$
(34) $T 6-T \infty=Q 34 \times R 34$
(35) $Q 3=Q 4+Q 6$
(36) $Q 4=Q 5+Q 7+Q 30-W 3$
(37) $Q 5=Q 8+Q 9$
(38) $Q 6+Q 7+Q 8=Q 12$
(39) $Q 10+Q 12=Q 11+Q 28+Q 34$
(40) $Q 9=Q 13+Q 15$
(41) $Q 11+Q 15=Q 18$
(42) $Q 13=Q 14+Q 16$
(43) $Q 16+Q 18=Q 19$
(44) $Q 14=Q 17+Q 21$
(45) $Q 17+Q 19=Q 20$
(46) $Q 21=Q 32+Q 22$
(47) $Q 32=Q 26+Q 23+Q 31-W 14$
(48) $Q 26=Q 24+Q 27$
(49) $Q 20+Q 22+Q 23+Q 24=Q 25$
(50) $Q 1=Q 2$
(51) $Q 28=Q 29$
(52) $Q 2+Q 33=Q 3+Q 10$

(Description of symbol)

$T:$ Node temperature

$Q$ : Heat flow value

$R$ : Heat resistance 


$$
\begin{aligned}
& L: \text { length in the direction of convection }(\mathrm{m}) \\
& A: \text { surface area }\left(\mathrm{m}^{2}\right)
\end{aligned}
$$

Therefore, from the Kirchhoff's law, the natural convection heat resistance R28 can be given by Eq. (9).

$$
R 28=\Delta T / Q_{c}=1 /\left(\alpha(\Delta T / L)^{0.25} \cdot A\right) \cdot
$$

Other heat resistances will be obtained in the same way.

(2) Vertical heat conduction element (R10, R11, R13, R14 R18, R19)

For example, R10 shows a resistance of heat flow path formed by a vertical heat conduction of the cylindrical surface of power source case, wherein the heat conduction value $Q_{d}$ is given by Eq. $(10)^{2)}$.

$$
Q_{d}=\kappa / L \cdot A_{1} \cdot \Delta T
$$

where $\kappa$ : heat conductivity of material $\left(\mathrm{W} / \mathrm{m}^{\circ} \mathrm{C}\right)$

A. : cross-sectional area $\left(\mathrm{m}^{2}\right)$

$L$ : Length in the direction of conduction (M). On the other hand, the cross-sectional area $A_{1}$ and the heat resistance R10 are given by Eq.11 and Eq.12, respectively ${ }^{2}$.

$$
\begin{aligned}
& A_{l}=\pi / 4\left(D 2^{2}-D 1^{2}\right) \cdots \cdots \\
& R 10=\Delta T / Q_{d}=L /{ }^{2} \cdot A_{1}
\end{aligned}
$$

where $\mathrm{D}_{1}$ and $\mathrm{D}_{2}$ : inside and outside diameter of power source case, respectively (m).

(3) Horizontal heat conduction element (R15,R16,R17)

For example, R15 shows a resistance of heat flow path formed by a heat conduction of the insulating base plate, if a radial heat flow exists. The heat conduction value $Q$ on the insulating base plate and the resistance R15 are given by Eq. (13) and Eq. (14), respectively ${ }^{2)}$.

$$
\begin{aligned}
& Q=2 \pi t \kappa /(\operatorname{lnd} 2 / d 1) \cdot\left(T_{c}-T_{0}\right) \ldots \ldots \ldots . . . \\
& R 15=\left(T_{c}-T_{0}\right) / Q=(\operatorname{lnd} 2 / d 1) /(2 \pi t \kappa)
\end{aligned}
$$

where $t:$ thickness of base plate $(\mathrm{m})$

$\mathrm{d} 1 \mathrm{:}$ inside diameter of base plate $(\mathrm{m})$

$\mathrm{d} 2$ : outside diameter of base plate $(\mathrm{m})$

$\kappa$ : heat conductivity $\left(\mathrm{W} / \mathrm{m}^{\circ} \mathrm{C}\right)$

$\mathrm{T}_{\mathrm{C}}$ : temperature at the center of base plate $\left({ }^{\circ} \mathrm{C}\right)$

$\mathrm{T}_{0}$ : temperature at the periphery of base plate $\left({ }^{\circ} \mathrm{C}\right)$.

(4) Radiation heat transfer element (R30,R31,R33,R34)

R31 shows a resistance of heat flow path formed by a radiation heat transfer from the light tube to the outside, wherein the radiation value Q31 is given by Eq. (15) in accordance with the Stefan-Boltzmann's law ${ }^{2)}$.

$$
\begin{aligned}
Q 31= & \varepsilon \sigma A\left\{(T 14+273)^{4}-\left(T_{\infty}+273\right)^{4}\right\} \\
= & \varepsilon \sigma A\left\{(T 14+273)^{2}+\left(T_{\infty}+273\right)^{2}\right\} \\
& \left\{(T 14+273)+\left(+T_{\infty}+273\right)\right\} \Delta T \cdot .
\end{aligned}
$$

where $\varepsilon$ : emissivity

$$
A: \text { surface area }\left(\mathrm{m}^{2}\right)
$$

Therefore, heat radiation resistance R31 is given by Eq. (16).

$$
\begin{aligned}
R 31= & \Delta T / Q 31=1 / \varepsilon \sigma A\left\{(T 14+273)^{2}+\left(T_{\infty}+273\right)^{2}\right\} \\
& \left\{(T 14+273)+\left(T_{\infty}+273\right)\right\} \ldots \ldots \ldots \ldots \ldots \ldots . . . \cdots \cdots
\end{aligned}
$$

Furthermore, R33, R34 are heat resistance for simulating the influence of emissivity $\varepsilon$ of power source case, which can be obtained in the- same way as above-mentioned.

(5) Directly given heat resistance element

(a) R1, R25, R27, R29
For example, since the natural convection from the light tube or the lower part thereof increases the ambient temperature around the power source case, the ambient temperature around the power source case will become higher than the atmospheric temperature. This phenomena can be expressed by a simplified model provided with such a resistance between each spatial node and the atmosphere. However, such a resistance is a natural convection element so that it is difficult to show this value by using a flow node ${ }^{4)}$. Therefore, this heat resistance value of $10-20\left({ }^{\circ} \mathrm{C}\right.$ $/ \mathrm{W})$ was determined by comparing it with the experimental value as described later.

\section{(b) R6, R7, R8}

These are a resistance for showing a temperature balance within the power source case. For example, while even only $\mathrm{R} 7$ and $\mathrm{R} 12$ can express the radiation from the heat generating element, an equalization of the temperature within the power source case by convection can ocurr. Such a resistance was defined for explaining such an equalization of temperature but it is dificult to formulate this phenomena so that this resistance value was determined by comparing it with the experimental value as described later.

\section{Solution Method}

As above-mentioned, among the heat resistances of the thermal network model shown in Fig.3 only a few can be calculated at the start so that it is necessary to give each heat resistance a flexibility for selecting a calculation data from a data base constructed by measured values. A flowchart of this solution method is shown in Fig.4. Since the solution method includes unknown quantity such as temperature $\mathrm{T}$ in the heat resistance of convection and radiation, the system of equations as shown in Table 3 becomes nonlinear, thereby an iterative calculation being required. As shown in the flowchart, the heat resistance is calculated by assuming the temperature of each node at the start and then the system of equations described in the previous chapter is solved. Here, the calculated temperature is compared with the assumed temperature. If both temperatures did not agree, the same calculation process shall be iterated by using an obtained temperature until the assumed temperature and the calculated temperature will agree with each other.

\section{Determination of Experimental Constant}

\subsection{Experiment}

The experimental constant ( $\alpha$ in Eq. (9)) and the notformulated heat resistance value in this simulation model was determined by an experiment in which a heater as shown in Fig.5 was used. In this experiment, the heat value $Q_{B}$ shown in Eq. (1) is controlled by an input power to the heater which thermally simulated the operating circuit part. The heater will generate a Joule heat as shown in Eq. (17).

$$
Q_{B}=I^{2} \cdot R
$$

where $R$ : resistance of heater

$I$ : current.

Furthermore, the lamp power or heat value $Q_{\mathrm{L}}$ (in Eq. (1)) of the light tube is approximated by Eq. (18), wherein the 
light tube is operated by a private external circuit.

$$
Q_{L}=I_{L} \cdot V_{L} \cdot \cos \phi
$$

where $I_{L}$ : lamp current

$V_{L}:$ lamp voltage

$\cos \phi$ : lamp power factor.

As the experimental parameters, the following items were selected as shown in Table 4.

(a) Size of power source case

(b) Emissivity of power source case

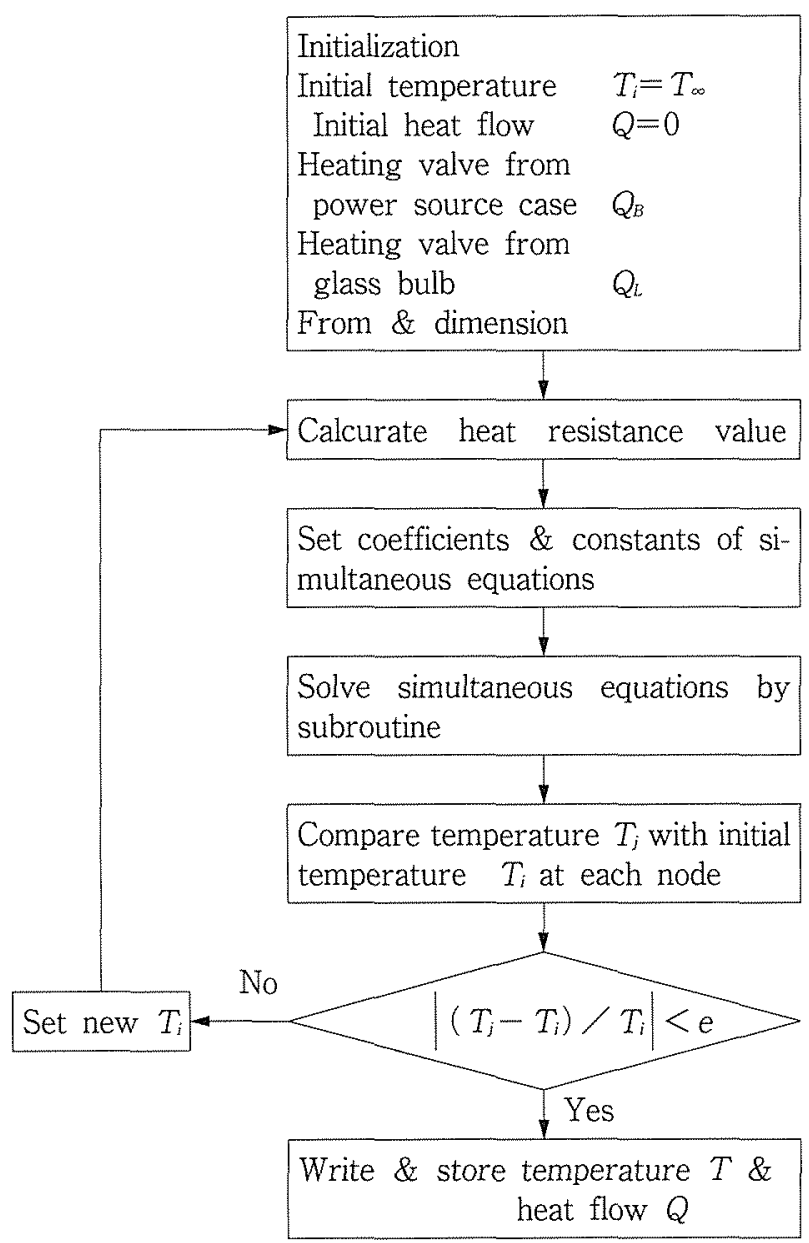

Fig. 4 Flowchart of solution method

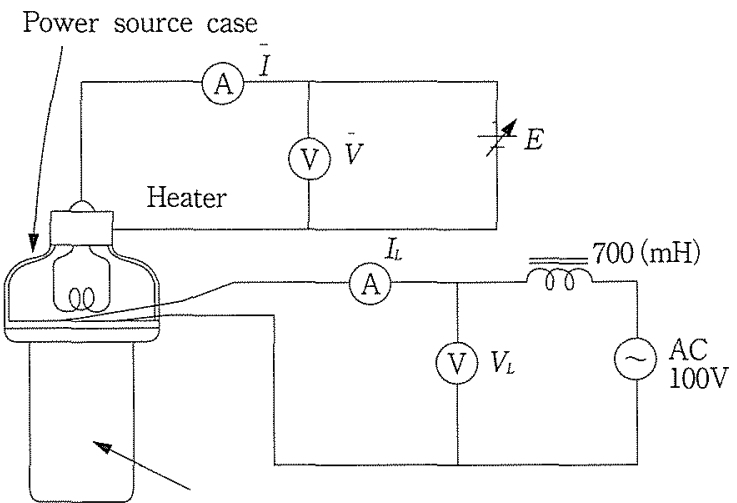

Light tube

Fig. 5 Experimental circuit (c) Heat conductivity of power source case

(d) Thickness of base plate.

The form of light tube was approximated by a cylindrical form and the experimental value and the calculated value were compared concerning the temperature at the inside and outside of the power source case. Fig. 6 shows the comparison between the experimental value and the calculated value.

\subsection{Determination of Experimental Constant}

Now, the experimental constant in Eq. (9) is determined as follows. At first, by comparing the experimental value with the calculated value in No.I case of Table 4, each constant value is determined such that the both values of temperature agree at each point. After determined, each constant value is fixed and then the calculation is transfered from No.1 case to No.2 case for a follow-up comparison. In this step, an ability of general-purpose use of this program is confirmed. Although it is a task of this study to give the experimental constant a general-purposeness for:

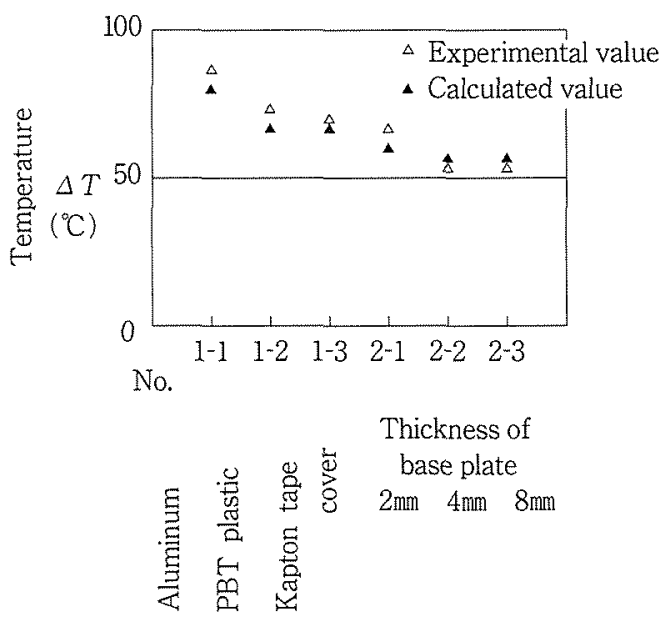

Fig. 6 (a) Comparison between experimental value and calculated value (within case)

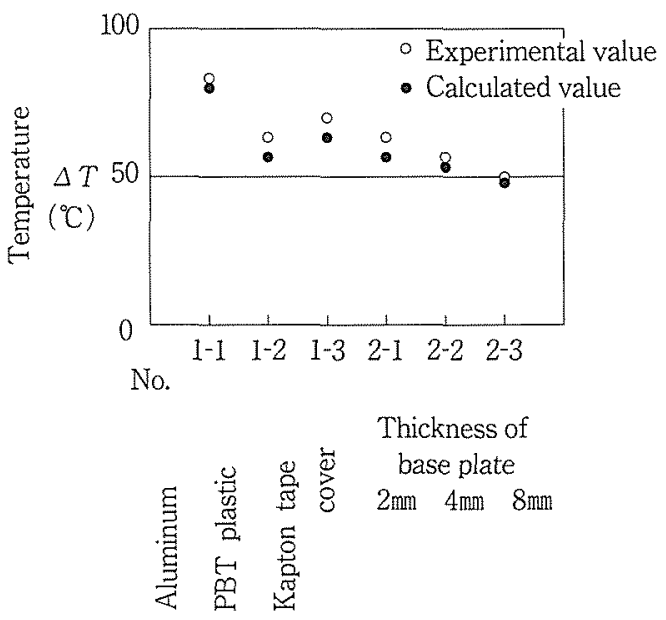

Fig. 6 (b) Comparison between experimental value and calculated value (on the external wall of case) 
Table 4 Parameter

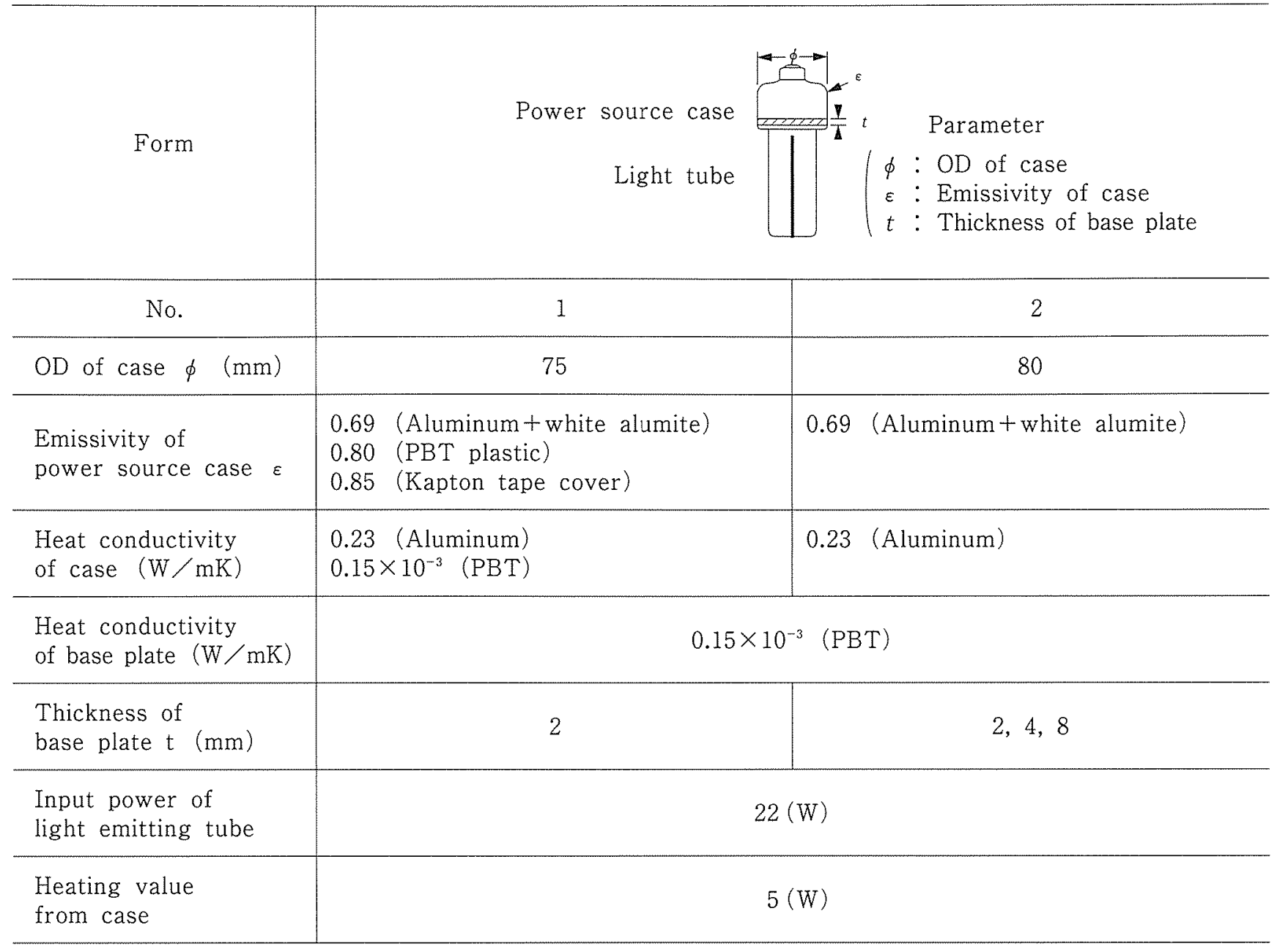

(1) Change of emissivity and heat conductivity of power source case in No.1 case,

(2) Change of base plate thickness in No 2 case

(3) Change of size of power source case in No.l and No. 2 case, it can be understood from the good correspondence of each value in Fig.6 that the determined constant values are appropriste.

\section{Application of Thermal Simulation}

6.1 Comparison of Calculated Value with Experimental Value

Fig.7 shows a comparison of the calculated value with the experimental value in this simulation. In the figure, $\Delta$ $\mathrm{T}$ shows a temperature rise from the atmospheric temperature. Under the condition of $27 \mathrm{~W}$ of input power, $85 \%$ of circuit efficiency, constant form and dimension and $1 \mathrm{~mm}$ of power source case thickness, the material of power source case was varied (aluminum, plastic (PBT)) and the outside diameter of power source case was also varied $(65 \mathrm{~mm}$, $70 \mathrm{~mm}$ ). In Fig.7, each of conditions (1),(2) has a good agreement between the calculated value and the experimental value, thereby showing that this simulation is fundamentally appropriate.

\subsection{Application of Thermal Simulation}

As shown in Fig.8, according to this simulation, not only

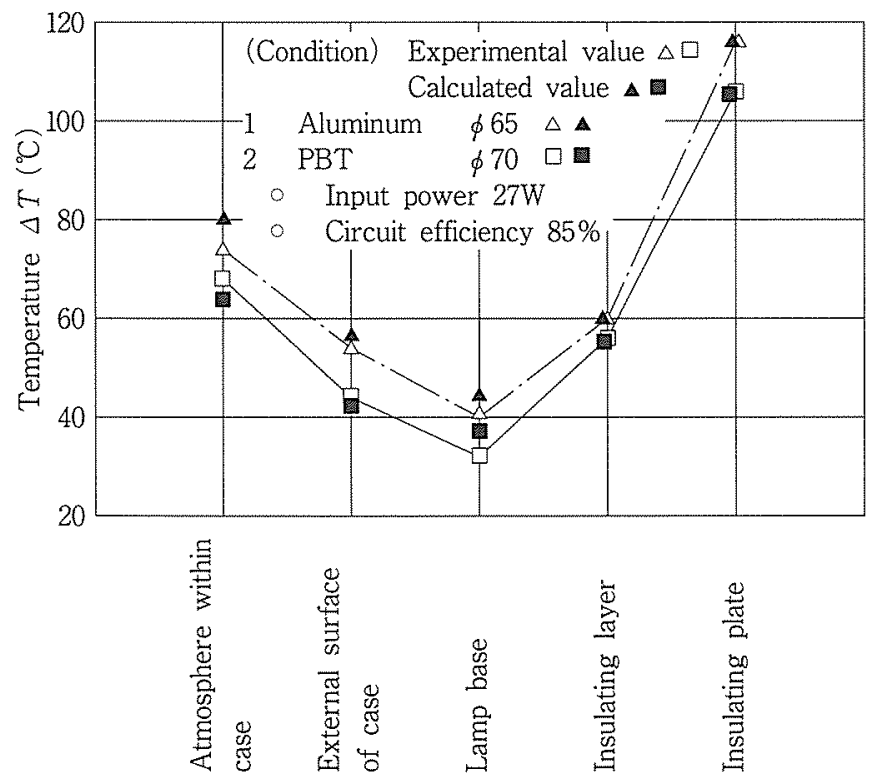

Fig. 7 Comparison between calculated value \& experimental value

the temperature of each point can be assumed depending on each variation of condition but also the direction and 


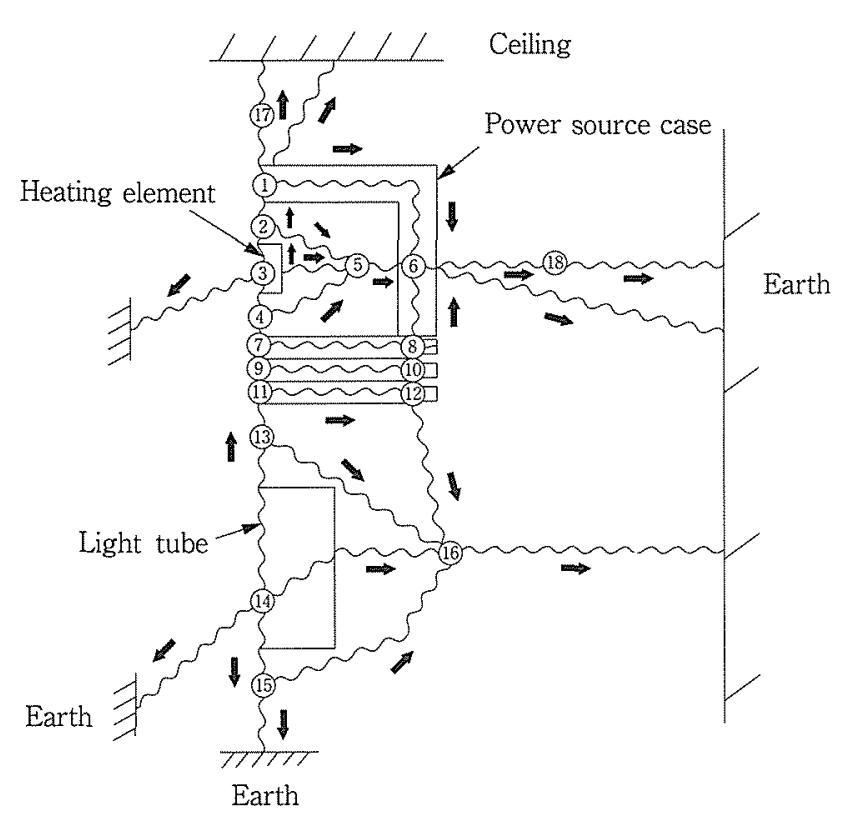

Fig. 8 Heat flow model of compact self-ballasted fluorescent lamp

the amount of heat flow through each resistance can be obtained. From the same figure, in which the thickness of arrow shows an amount of heat flow value, it is clear that among a number of heat flows the heat flow (a) from light tube to power source case, (b) from power source case to atmosphere and (c) from light tube to atmosphere is large in particular, Therefore, such a heat flow will be considered as an important factor in the thermal design. Some examples of the application of this simulation to a thermal design will be described hereafter.

(1) Effect of insulating air-layer

Simulation results of the relation between the thickness and the thermal shield effect of the insulating air-layer, when the resistance R16 (Fig.3) for shielding the heat flow as shown in the above (a) was replaced with an insulating air-layer, are shown in Fig.9. Even in a small thickness of insulating air-layer such as $1 \mathrm{~mm}$, a thermal shield effect can be confirmed by a temperature lowering of about $10^{\circ} \mathrm{C}$ When the thickness of air-layer is increased, the effect of

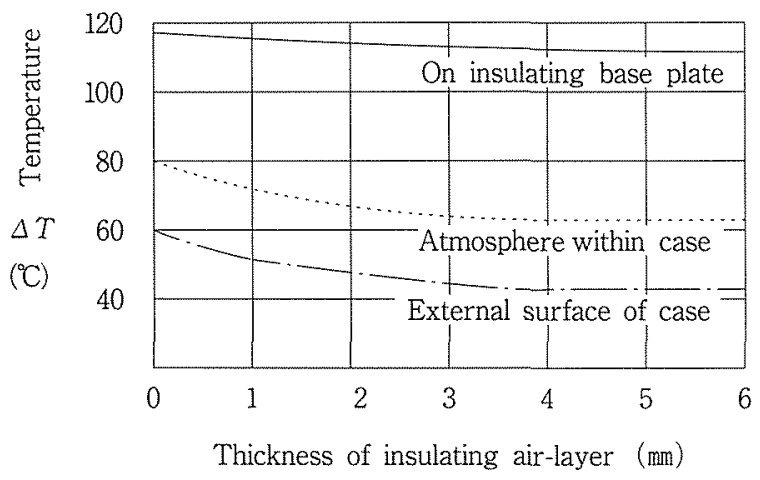

Fig. 9 Relation of thickness of insulating air-layer with each node temperature by simulation temperature lowering is also increased but it will be saturated at the thickness of $3 \mathrm{~mm}$. Therefore, it is expectable that the insulating air-layer of $3 \mathrm{~mm}$ is appropriate in this case.

(2) Outside Diameter of Power Source Case

Simulation results at the different outside diameter $(65 \mathrm{~mm}$, $70 \mathrm{~mm}, 75 \mathrm{~mm}$ ) of power source case (Fig.3) are shown in Fig.10. The simulation was carried out under the condition of the material of power source case of PBT plastic (emissivity : 0.80 , heat conductivity : $0.15 \times 10^{-3} \mathrm{~W} / \mathrm{mk}$ ), the thickness of $1 \mathrm{~mm}$, the lamp power of $27 \mathrm{~W}$ and the circuit efficiency of $85 \%$. It is found out that the temperature within the case was lowered by about $15^{\circ} \mathrm{C}$ by increaseing the outside diameter of the case from $65 \mathrm{~mm}$ to $70 \mathrm{~mm}$ due to the increase of heat emitting surface area but when the outside diameter was increased from $70 \mathrm{~mm}$ to $75 \mathrm{~mm}$ the temperature lowering was only about $5^{\circ} \mathrm{C}$ due to a trend of saturation, Therefore, it is expectable that the outside diameter of power source case of about $70 \mathrm{~mm}$ is appropriate.

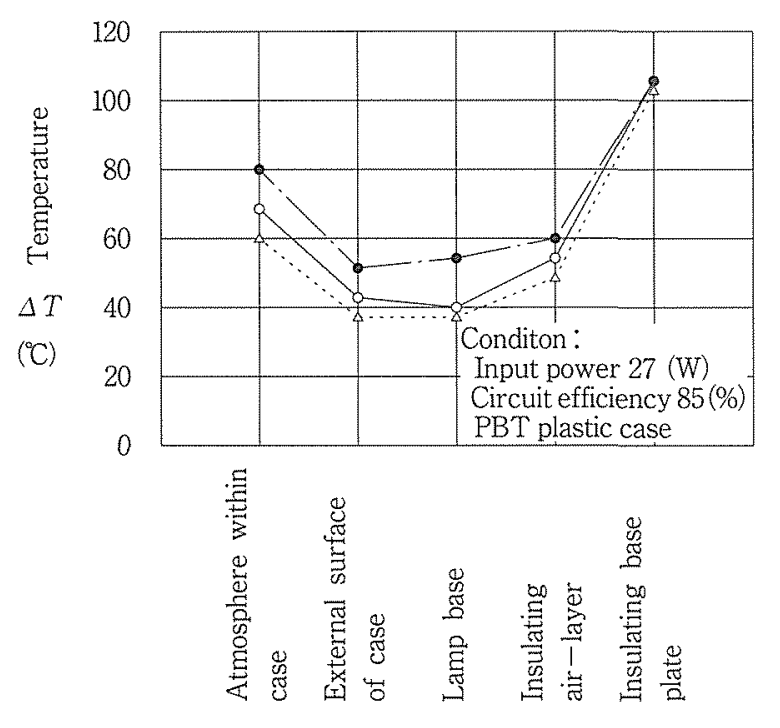

Fig. 10 Relation of OD of power source case with each node temperature by simulation

\section{Conclusion}

By introducing the thermal network equations into an analysis of compact self-ballasted fluorescent lamp, a simulation model was constructed, wherein simultaneous equations with 52 elements of 18 temperature nodes and 34 heat resistances, which explain the heat transfer modes, were formulated. Furthermore, the experimental constants which were introduced for formulating the above-mentioned equations were determined from an experiment simulating the operating circuit part by a heater. An appropriateness of this model was confirmed by a good agreement between the calcuated value and the experimental value of temperature at each node in a steady state, wherein the temperature was calculated by using these constants.

In this model, not only the temperature but also the heat flow depending on parameters can be estimated. Therefore, this model will be useful for thermally designing the compact self-ballasted fluorescent lamp from the point of optimum and rapid structure design. 
Although the formation of model of the compact selfballasted fluorescent lamp without external bulb was studied this time, this method will be capable of being expanded to a heat transfer model including the type with external bulb and the lighting fixture in future by means of

(1) preparation of properties value of glass, e.g. absorp tivity

(2) introduction of spectral properties into heat transfer equation.

\section{References}

(1) Inoue, Umeoka, Kimura, Ogata : "High-Illuminance
Fluorescent Lamp", Toshiba Review 42-9 (1987) $658-661$

(2) Y.Kodo: "An Introduction to Electro-Heat Transfer", Yokendo 410 (1973) 5-57

(3) M.Ishizuka, Y.Fukuoka: "Transient Temperature Rise of Multi-Chip Package Board" Trans. of Jpn. Soc. Mech. Eng. 52-476 (1986-4) 1172-1775

(4) Ishizuka, Sasaki, Yokono, Makita, Suzuki : "Discussion on Introduction of CAE to Thermal Design of Electronic Device" Gen. Seminar of Electon. Info. \& Comm. Inst. Jpn. (1987) 126 